\title{
Taking Blockchain Seriously
}

\author{
Robert Herian ${ }^{1}$
}

Published online: 12 May 2018

(C) The Author(s) 2018

\begin{abstract}
In the present techno-political moment it is clear that ignoring or dismissing the hype surrounding blockchain is unwise, and certainly for regulatory authorities and governments who must keep a grip on the technology and those promoting it, in order to ensure democratic accountability and regulatory legitimacy within the blockchain ecosystem and beyond. Blockchain is telling (and showing) us something very important about the evolution of capital and neoliberal economic reason, and the likely impact in the near future on forms and patterns of work, social organization, and, crucially, on communities and individuals who lack influence over the technologies and data that increasingly shape and control their lives. In this short essay I introduce some of the problems in the regulation of blockchain and offer counter-narratives aimed at cutting through the hype fuelling the ascendency of this most contemporary of technologies.
\end{abstract}

Keywords Blockchain $\cdot$ Data $\cdot$ Neoliberalism $\cdot$ Regulation $\cdot$ Technology

\section{Introduction}

Part of what Manuel Castells called the rise of network society (Castells 2010), as well as falling within the scope of notions of ubiquitous or pervasive computing and ambient intelligence promoted by the likes of IBM in the latter part of the twentieth century (Wright et al. 2006, pp. 7-9), distributed ledger technology (DLT), or as it is popularly known blockchain, is impacting and in many cases transforming thought and practice in information and communication technology and beyond.

Robert Herian

robert.herian@open.ac.uk

1 The Faculty of Business and Law, The Open University Law School, The Open University, Milton Keynes MK7 6AA, UK 
For example, the technology is viewed by some stakeholders as necessary in order to address, once and for all, the problematic of inefficient and ineffective systemic and institutional intermediation, otherwise known as the middleman. In this essay I argue that blockchain needs to be taken seriously from the point of view of regulation, and briefly introduce some regulatory themes for consideration. ${ }^{1}$ First, however, what makes the emergence of blockchain technology within the contemporary politico-economic landscape not only a viable but a crucial target of critique?

\section{Believing the Hype}

A Financial Times report on the World Economic Forum in Davos, Switzerland, in January 2018 carried the headline 'blockchain can no longer be ignored' (Arnold 2018). Whilst focus on blockchain by economic elites in Davos arguably stems from perceived and potential threats to legacy financial control and power, which cryptocurrencies such as Bitcoin but also blockchain are said to represent by influential stakeholders in the blockchain ecosystem (Swan 2015; Tapscott and Tapscott 2016; Masters 2016), there is far more to the unfolding story of so-called blockchain 'disruption'. Hype surrounding the technology has been building significantly during the past three or four years based largely on the notion (and applied technological potential) of blockchain infrastructure as severable from and therefore not reliant on the problematic world of digital currencies. ${ }^{2}$ On that basis the gradual entry of blockchain into mainstream commercial consciousness has largely signalled a retreat and an uncoupling from anarchic libertarian aspirations harboured by those who first conceived of it. ${ }^{3}$ As a consequence the technology is no longer a threat to legacy financial power but yet another opportunity to be exploited by it. Put another way, blockchain offers myriad 'possible paths to improve system efficiency and scalability' that are attractive technological 'solutions' to global financial power, but that requires changing current models, which has strong implications for the centralization of a technology rooted in a decentralizing ethos (Aste et al. 2017, p. 26).

Interest in blockchain at Davos has shown (and for some time prior) that legacy financial power can easily absorb 'disruptive' technologies into existing paradigms and thus not be disrupted by them at all. Blockchain, it is believed, will enable systems of trade and finance to become more effective and efficient by supporting and

\footnotetext{
1 For a more detailed examination of the themes introduced in this essay, see: Herian (forthcoming).

2 A 2015 edition of The Economist that focused on blockchain as 'The Trust Machine' was arguably a key moment in the mainstreaming of the technology, as well as development of the idea that blockchain could do more than simply serve the purposes of those interested in trading and using cryptocurrencies such as Bitcoin.

3 The result of this libertarian retreat, however, which began with Satoshi Nakamoto's claim in the now infamous White Paper that something akin to what is now called blockchain technology would enable individuals to transact online without 'going through financial institutions' (Nakamoto 2008, p. 1), does not automatically signal stronger democratic oversight by centralized governments. Rather, and in accord with the neoliberal tradition, it signals government and governance in the corporate commercial mould, summed up in Melanie Swan's vision of blockchain-led governance being 'services as individualized as Starbucks coffee orders' (Swan 2015, p. 46).
} 
realising (making viable and invisible) the advanced stages of global mass data handling and frictionless transfers of value-what Lana Swartz calls 'infrastructural care work' (Swartz 2017, p. 102) — thus transforming society and industry alike (Swan 2015; Tapscott and Tapscott 2016; Aste et al. 2017). The blockchain horizon is one in which more capitalism and with it the further and deeper entrenchment of capitalist class power are likely outcomes based on the present course of blockchain research, development and implementations. This is perhaps unsurprising however as blockchain is self-evidently a capitalist organizational form, or more specifically, to refer to capital's contemporary 'mutant form', a neoliberal one (Han 2017, p. 5). Where various national governments have begun to take blockchain seriously, including in the UK with the recent formation of an All Party Parliamentary Group (APPG) on blockchain, discussions tend to begin with advantages for entrepreneurs and investors, and favour commercial business applications first and foremost, with broader social benefits that the technology might herald remaining lower order considerations. $^{4}$

Amid the bluster of rampant innovationism that engenders the present sociopolitical moment, technologies such as blockchain have a guaranteed place in changes (whether subtle or sweeping) made to social structures, systems and institutions. 'Blockchain is more than a technology', Eva Kaili, Chair of the European Parliament's science and technology panel, has enthusiastically claimed, it is an infrastructure upon which we can build wider applications such as the Internet of Things, smart cities and infrastructures' (Singh 2017). Decentralization of state sovereignty and power in favour of coded and technological formations of economic and consumerist subjectivities, of dividuated data governance, to echo Deleuze (Deleuze 1995, p. 182), and underscored by neoliberal accusations 'that governments inevitably promote inefficient models of economic administration' (Stiegler 2010 , p. 101), is setting new precedents for the management of individuals as depoliticized, machine readable data auras. The present lack of or reluctance toward critical regulatory oversight threatens to result in an exclusive commercial dictate with little or no democratic or government accountability. On this basis it is imperative that critique questions, as it has done in relation to the growth of the Internet, mobile technologies and big data; what is (and will be) at stake from blockchain's continuing embeddedness in economic logic and reason; and to consider what other options might exist to benefit and empower community over self-interest.

\section{Political Assumptions}

Ian Bogost says of Bitcoin that it is a technology that seems to be 'from an alien civilization' (Bogost 2017). More importantly, however, he acknowledges that in order to understand it — and blockchain forms part of this consideration-'first requires

\footnotetext{
4 This perspective is drawn from the author's own experience as a contributing member of the UK's APPG blockchain group, which first convened on 30 January 2018. The UK government, prior to this, had explored blockchain in-depth in only one report by the Chief Scientific Advisor (Walport 2016).
} 
deciphering the political assumptions that inspire it' (Bogost 2017). Whether viewed as a database, network or distributed ledger, blockchain is much more to its promoters and acolytes than mere code or a computational tool for time-stamping data records and transactions. ${ }^{5}$ Likewise, to the uninitiated layperson increasingly hearing and seeing news reports on Bitcoin and other cryptocurrencies, there is more to the technology than mere computation. There is, it might be said based on events at the close of 2017 and the beginning of 2018, a certain thrill accompanying the possibility of great wealth as the value of a single Bitcoin hovers around $\$ 10,000$; or, equally, dismay at scandals and vulgar opportunism accompanying the digital gold-rush.

Cryptocurrencies and blockchain enfold a range of potentialities and promises, as well as threats and harms to the social. It is incumbent upon regulators, and governments more broadly, to maintain a grip on the extent of the social and political reach the technology has, and not abdicate that responsibility to chaotic entrepreneurs and private commercial entities intent on 'making up sets of rules' and engaging in 'freelance governance' (Gupta 2017). Decentralization of legacy forms of power and the radical reimaging of paradigms of trust, transparency and even democracy, all make blockchain politically determinative. Moreover, blockchain is a striking moment, if not precisely a unique phenomenon, within the long durée of technology with capitalism. ${ }^{6}$ This is an important truth that needs to be maintained before the technology is allowed to sink into the mire of everyday economic logic, reason and practice and thus become invisible as another piece in the jigsaw of neoliberal common sense.

Blockchain critique is important at this moment because the technology remains undefined in the wider public consciousness and therefore its politics are not set. This point is important because blockchain's legitimacy and authority does not, I argue, derive from technological credentials, but from being a (relatively) novel lens through which to view the world undertaking a fourth industrial revolution and the potential to order and control people, institutions, systems and networks in that world. In an interesting and wonderfully cynical article, Kai Stinchcombe asks why nobody has found a use for blockchain in the 10 years of its existence (Stinchcombe 2017). He suggests this is due to the fact that multiple technologies already exist that are able to do what people would like, for whatever reason, to see blockchain doing. In short, blockchain is simply not needed. Whilst Stinchcombe's article raises some interesting points, it misses a key one: blockchain produces greater effects as an idea than an applied technology. Blockchain is a powerful cultural and political product that has emerged from turbulent conditions post-financial crisis and it derives legitimacy and authority from promises of inter alia radical transparency that are tantalizing yet rightly brought into question (Han 2015; Pasquale 2015).

\footnotetext{
5 Time-stamping documents and recording them on a digital ledger is a basic way in which to describe the function of a blockchain, and relates to an earlier system developed in the late 1980s of which today's ledgers are the progenitor: see, for example, Haber and Stornetta (1991).

6 Alexander Galloway makes similar arguments around the material effects of protocol, what he defines as 'the standards governing the implementation of specific technologies [...] a technique for achieving voluntary regulation within a contingent environment' (Galloway 2004, p. 7).
} 


\section{A Regulatory Conundrum}

In The Regulatory Enterprise, Tony Prosser proposes two regulatory visions at once in dialogue and polar opposition-although he does acknowledge that a great deal of light and shade generally constitute regulatory environments and space (Prosser 2010, p. 4). There is a 'major distinction', claims Prosser, 'between regulation as infringement of private autonomy and regulation as a collaborative enterprise' (Prosser 2010, p. 4), and this, I suggest, lies at the heart of the blockchain regulatory conundrum. ${ }^{7}$ For present purposes the former can be said to accord with a vision of the blockchain ecosystem and conduct based in market-complementing regulation, economic efficiency and self-interest, and what Prosser further refers to as 'regulation for economic efficiency and consumer choice' (Prosser 2010, p. 18); the latter to social or distributive concerns, community and generosity (Cohen 2011, pp. 217-219), or what Prosser aligns to 'regulation for social solidarity' and 'regulation as deliberation' (Prosser 2010, p. 18). A fourth regulatory framework highlight by Prosser concerns the protection of rights (Prosser 2010, p. 18); regulation therefore rooted in domestic and trans-national legislative frameworks, as well as international law and treaties, which do not necessarily favour either the polarity of markets and self-interest or community and generosity unless predisposed to do so by law.

The current task of understanding what regulating blockchain means or ought to mean is occurring against a backdrop of continuing struggles to achieve meaningful and stable regulation and governance over commercial platforms, within networks, and in consideration of interoperability and the broader architecture of the Internet. The questions, problems and so on that blockchain brings to the fore are therefore not easily abstracted from many of the concerns that continue to plague regulation of Internet-based networks and systems. Shortcomings in Internet regulation remain stubbornly apparent some 30 years into the mass adoption of the technology (Brown and Marsden 2013; Mueller 2013; Pasquale 2015; Srnicek 2017) and the how's and why's of blockchain regulation now form part of, but have also arguably intensified, the regulatory conundrum. There are a number of reasons for this claim, but the one of most interest here concerns the co-evolution of technology and economy and, importantly, the cultural and political ramifications of this and how regulatory environments, enterprise and rationale address them. If, for example, it is true that the

\footnotetext{
7 This distinction is made more apparent when the nature of different blockchains is taken into consideration. Namely, permissioned ledgers, which, as the name suggests, are designed for use on closed, private systems by those with the requisite permissions (e.g. to create 'transparent' and 'immutable' information and data audit trails within the confines of a global corporation); in contrast to permission-less ledgers like the Bitcoin blockchain which maintain a public character and are therefore more open to scrutiny. A great deal of research, development and subsequent discussion surrounding actual use-cases for blockchain technology has now moved onto the role of permissioned ledgers for back-office functions in, for example, banking systems. The irony of this, given the initial libertarian (i.e. avoidance of financial institutions) aspirations the technology was said to engender, is unmistakable. As David Golumbia remarks, this irony is symptomatic of 'a reassertion of the political power that the blockchain is specifically constructed to dismantle' (Golumbia 2016, p. 76; see also, Herian 2016, 2018). Moreover, as Lana Swartz has argued, the 'incorporative blockchain' of back-office functions is no longer pursuing the libertarian dream of holistically remaking society, but is, in fact, quite 'boring' (Swartz 2017, p. 96).
} 
'economy is an expression of its technologies' (Arthur 2009, p. 193), it is equally so, I claim, that technologies are the expression of economic will, and the present blockchain moment is both illustrative and symptomatic of the latter.

The emergence of blockchain 'disruption' within the contemporary political and economic moment calls to mind Joseph Schumpeter's notion of creative destruction (Schumpeter 2010). In the hands of quasi-libertarian, self-interested and, what Vinay Gupta (2017) has called, 'chaotic' entrepreneurs, this creative destruction has led, in the main, to myriad attempts at re-imagining (not disrupting) legacy financial systems over the last decade using cryptocurrencies. The desire now is to repeat the process in an array of non-currency based, normatively civic arenas such as e-voting, land registries and health records (Tapscott and Tapscott 2016). In practice this means growth in blockchain-based private public partnerships, or to put it another way, privatization of forms of public administration that puts them beyond direct democratic accountability (private corporate actors not being publicly elected officials), whilst amplifying the role of regulators ill-prepared for the task of dealing with high levels of bluster and noise emanating from the blockchain ecosystem As such, this also entails the so-called 'wait and see' or the somewhat more proactive 'wait and monitor' approaches to regulation adopted by the likes of the European Commission (Singh 2017).

Attempts by entrepreneurs to leverage personal, self-interested gains, through the re-imaging of various legacy systems, are occurring at the fuzzy edges of transnational regulatory understanding and lead to the threat of what I am calling regulatory disorientation. This means regulators are facing informational overload and that 'wait and see' or 'wait and monitor' approaches are mere euphemisms for a lack of motivation or energy across the regulatory environment whose focus on 'centralized actors in a decentralized ecosystem will not be able to keep pace' (Reyes 2016, p. 221). Jurisdictions have as a consequence reacted at different speeds; some slow, others with more urgency, especially in the case of cryptocurrency regulation, which has included in some cases outright bans on the trading and possibly also on the use of cryptocurrency. ${ }^{8}$ But as yet the majority of jurisdictions have said little and done less to define or impose limits on either blockchain, its ecosystem or the conduct it produces. This 'wait and see' approach, it would appear, signals a longer term project; a fact that is not necessarily unwelcome if that means serious critical scrutiny of the technology is undertaken (Walch 2017, p. 14).

Where it is a problem, however, is twofold: firstly, where the wait and see policy is beholden to innovationism or creates a vacuum that innovationism quickly fills, often made clear by calls from entrepreneurs and other stakeholders for government not to stifle innovation; ${ }^{9}$ secondly, in allowing the lag between law, regulation and

\footnotetext{
${ }^{8}$ The UK and EU are both presently considering the need to regulate cryptocurrency in order to address problems of anonymity apropos money laundering and tax evasion. Other nations, South Korea for instance, are also planning to ban cryptocurrency trading for the same reasons. See for example: Kollewe (2017).

${ }^{9}$ The European Commission is illustrative again here, where both Eva Kaili and German EPP group MEP, Jacob von Weizsäcker, have backed regulatory approaches that do not 'regulate too early, so as to avoid stifling innovation' (Singh 2017).
} 
governance, and blockchain to grow in the interim. In both problems, which largely intersect, it is possible to recognise a repeat of the shortcomings and mistakes of Internet regulation, which have led to the hegemony of big data business and the mass commercialisation of cyberspace on the one hand, and a parallel ungovernable 'dark-net' on the other. Mueller (2017) reinforces this point, whilst also simultaneously celebrating innovation and highlighting failures in Internet regulation and governance. 'It has become a cliché', says Mueller, 'to note that the "unified and unfragmented space" created by the victory of the Internet protocols was filled not only with innovative economic and social activity, but also with the crimes and conflicts that accompany human interactions in every other space' [emphasis added] (Mueller 2017, p. 11). Thus, Mueller concludes, '[a]long with the innovations, efficiencies, and creative new forms of entertainment and interaction came thieves, bullies, fraudsters, child abusers, spies, vandals' (Mueller 2017, p. 11).

Whilst blockchain may not be considered a particularly risky technology in terms of potential threats or harms it poses to individuals or communities-compare this with, for example, cautionary tales surrounding 'the malign aspect of technology' (Arthur 2009, p. 215) including perceived threats from bioengineering, artificial intelligence and nanotechnologies (Brownsword 2008) - this does not mean that no threats or harms exist, but instead manifest in other, more subtle ways. There are for instance conceivable threats and harms posed by the blockchain ecosystem in further entrenching and disseminating neoliberal ideology for instance. For neoliberal stakeholders, but equally those who are simply complaisant about ill-effects of social and political control wrought by 'free-market' economics, this is unlikely to sound like a threat at all. For this class of stakeholder blockchain remains, for the better, 'an institutional technology to decentralize the governance structures used to coordinate people and economic decision making' (Aste et al. 2017). If, however, neoliberal ideology is grounded in what Stuart Hall called the anachronism of 'the free, possessive individual, with state cast as tyrannical and oppressive', whereby the state "must not intervene in the "natural" mechanisms of the free market, or take as its objective the amelioration of free-market capitalism's propensity to create inequality' (Hall 2017, p. 318), then what is at stake in the regulatory decisions that foster more neoliberalism in the blockchain context ought to be clear, questioned and ultimately challenged.

\section{Conclusion}

It is clear that ignoring the hype surrounding blockchain is unwise given its rapid proliferation. Echoing trends in technologies that have come before it, blockchain represents an 'increasingly influential yet subtle force in our lives' (Brenner 2007, p. 185). Regulators and governments especially need to get a grip on blockchain in order to ensure democratic accountability in the blockchain ecosystem and beyond; to ask whether the technology and the regulatory goals attached to it are 'proportionate and limited to what is necessary to protect a specific public interest in a democratic society' (Wright et al. 2006, p. 156). Blockchain is a product of the shifts and tensions in political and socio-economic thought and practice since the financial 
crisis of 2008. As a discourse or text blockchain recounts a broad matrix of socioeconomic and political issues in a constant state of flux. Moreover it is revealing something very important about the evolution of the subject caught in the force-field of neoliberal economic reason both at the macro level of contemporary free-market capitalism, and more intimately. Blockchain further highlights for example: the subject's encounter with the (im)materialism of digital objects; big data and the digital unconscious; as well as the ability of technologies to produce and distort meaning, as well as (re)constitute being and memory. These issues are technologically informed social, political, as well as psychological, concerns that deserve serious analysis. The consequences of change in communities and the lives of individuals who already lack influence over the technologies, networks, platforms and data that presently shape, control and yet provide meaning, is key to the unravelling story of blockchain. For better or worse, understanding a future with blockchain is imperative. From a critical perspective it may not be all about blockchain (Tapscott and Tapscott 2016), but it is certainly the case that blockchain can no longer be ignored.

Open Access This article is distributed under the terms of the Creative Commons Attribution 4.0 International License (http://creativecommons.org/licenses/by/4.0/), which permits unrestricted use, distribution, and reproduction in any medium, provided you give appropriate credit to the original author(s) and the source, provide a link to the Creative Commons license, and indicate if changes were made.

\section{References}

Arnold, Martin. 2018. Davos: Blockchain can no longer be ignored. Financial Times. 24 January. https:// www.ft.com/content/c0794556-ff50-11e7-9650-9c0ad2d7c5b5. Accessed 1 February 2018.

Arthur, W. Brian. 2009. The nature of technology: What it is and how it evolves. London: Penguin.

Aste, Tomaso, Tasca, Paolo and Di Matteo, Tiziana. 2017. Blockchain technologies: The foreseeable impact on society and industry. Computer 50(9): 18-28.

Bogost, Ian. 2017. Cryptocurrency might be a path to authoritarianism. The Atlantic. 30 May. https:// www.theatlantic.com/technology/archive/2017/05/blockchain-of-command/528543/. Accessed 25 January 2018.

Brenner, Susan W. 2007. Law in an era of 'smart' technology. Oxford: Oxford University Press.

Brown, Ian, and Christopher T. Marsden. 2013. Regulating code: Good governance and better regulation in the information age. Cambridge: MIT Press.

Brownsword, Roger. 2008. Rights, regulation, and the technological revolution. Oxford: Oxford University Press.

Castells, Manuel. 2010. The rise of the network society, 2nd ed. Chichester: Wiley Blackwell.

Cohen, G.A. 2011. On the currency of egalitarian justice, and other essays in political philosophy, ed. Michael Otsuka. Princeton: Princeton University Press.

Deleuze, Gilles. 1995. Negotiations 1972-1990, trans. Martin Joughin. New York: Columbia University Press.

De, Nikhilesh. 2018. German Central Bank: Cryptocurrencies must be regulated on a global scale. CoinDesk, 15 January. https://www.coindesk.com/german-central-banker-cryptocurrencies-must-beregulated-on-a-global-scale/. Accessed 16 January 2018.

Galloway, Alexander R. 2004. Protocol: How control exists after decentralization. Cambridge: MIT Press.

Golumbia, David. 2016. The politics of Bitcoin: Software as right-wing extremism. Minneapolis: University of Minnesota Press.

Gupta, Vinay. 2017. European Parliament blockchain presentation May 2017. YouTube. https://www. youtube.com/watch?v=xEFVuccuHI8\&t=4s. Accessed 1 February 2018. 
Haber, Stuart, and Stornetta, W. Scott. 1991. How to time-stamp a digital document. Journal of Cryptology 3(2): 99-111.

Hall, Stuart. 2017. Selected political writings: The great moving right show and other essays, ed. Sally Davison, David Featherstone, Michael Rustin, and Bill Schwartz. Durham: Duke University Press.

Han, Byung-Chul. 2015. The transparency society, trans. Erik Butler. Stanford: Stanford University Press.

Han, Byung-Chul. 2017. Psycho-politics: Neoliberalism and new technologies of power, trans. Erik Butler. London: Verso.

Herian, Robert. 2016. Anything but disruptive: Blockchain, capital and a case of fourth industrial age enclosure, part I \& II. October. https://www.critciallegalthinking.com. Accessed 30 January 2018.

Herian, Robert. 2018. Blockchain and the distributed reproduction of capitalist class power. In MoneyLab Reader 2: Overcoming the hype, ed. Inte Gloerich, Geert Lovink and Patricia de Vries. Amsterdam: Institute of Network Cultures. http://networkcultures.org/. Accessed 12 January 2018.

Herian, Robert. Forthcoming. Regulating blockchain. London: Routledge.

Kollewe, Julia. 2017. Bitcoin: UK and EU plan crackdown amid crime and tax evasion fears. The Guardian, 4 December. https://www.theguardian.com/technology/2017/dec/04/bitcoin-uk-eu-plan-crypt ocurrency-price-traders-anonymity. Accessed 12 January 2018.

Masters, Blythe. 2016. Blockchain: Will it change your life? YouTube. 17 October. https://youtu.be/ v2V4HzuhfV4. Accessed 30 March 2018.

Mueller, Milton M. 2013. Networks and states: The global politics of internet governance. Cambridge: MIT Press.

Mueller, Milton. 2017. Will the Internet fragment? Sovereignty, globalization and cyberspace. Cambridge: Polity.

Nakamoto, Satoshi. 2008. Bitcoin: A peer-to-peer electronic cash system. https://bitcoin.org/bitcoin.pdf. Accessed 23 March 2017.

Pasquale, Frank. 2015. The black box society: The secret algorithms that control money and information. Cambridge: Harvard University Press.

Prosser, Tony. 2010. The regulatory enterprise. Oxford: Oxford University Press.

Reyes, Carla L. 2016. Moving beyond Bitcoin to an endogenous theory of decentralized ledger technology regulation: An initial proposal. Villanova Law Review 61(1): 191-234.

Schumpeter, Joseph A. 2010. Capitalism, socialism and democracy. London: Routledge.

Singh, Rajnish. 2017. EU must work to enable blockchain technology. The Parliament Magazine, 7 November. https://www.theparliamentmagazine.eu/articles/opinion/eu-must-work-to-enable-block chain-technology. Accessed 31 March 2018.

Srnicek, Nick. 2017. Platform capitalism. Cambridge: Polity.

Stiegler, Bernard. 2010. For a new critique of political economy, trans. Daniel Ross. Cambridge: Polity.

Stinchcombe, Kai. 2017. Ten years in, nobody has come up with a use for blockchain. Hacker Noon, 22 December. https://hackernoon.com/ten-years-in-nobody-has-come-up-with-a-use-case-for-block chain-ee98c180100. Accessed 31 January 2018.

Swan, Melanie. 2015. Blockchain: Blueprint for a new economy. Sebastopol: O’Reilly.

Swartz, Lana. 2017. Blockchain dreams: Imagining techno-economic alternatives after Bitcoin. Another economy is possible, ed. Manuel Castells. Cambridge: Polity Press, 82-105.

Tapscott, Don, and Tapscott, Alex. 2016. Blockchain revolution: How the technology behind Bitcoin is changing money, business and the world. London: Portfolio Penguin.

Walch, Angela. 2017. Blockchain's treacherous vocabulary: One more challenge for regulators. Journal of Internet Law 21(2): 9-16.

Walport, Sir Mark (UK Government Chief Scientific Adviser). 2016. Distributed ledger technology: Beyond block chain. Government Office for Science. 19 January. https://www.gov.uk/government/ publications/distributed-ledger-technology-blackett-review. Accessed 31 January 2018.

Wright, David, Michael Friedewald, and Elena Vildjiounaite, eds. 2006. Safeguards in a World of Ambient Intelligence (SWAMI). Deliverable D1. The brave new world of ambient intelligence: A state-ofthe-art review. Contributing authors: David Wright, Elena Vildjiounaite, Ioannis Maghiros, Michael Friedewald, Michiel Verlinden, Petteri Alahuhta, Sabine Delaitre, Serge Gutwirth, Wim Schreurs, Yves Punie. http://is.jrc.ec.europa.eu/pages/TFS/documents/SWAMI_D1_Final_001.pdf. Accessed 27 March 2018. 